\title{
Uplift Pressure Resistant Approach in Diaphragm Wall Excavation-case Study: Imam Hossein Holy Shrine Development -Karbala- Iraq
}

\author{
Behnam Eslami Ziraki', Vahid Ghasemi ${ }^{2}$ \\ ${ }^{1}$ Geotechnical Engineering, Department of Soil and Foundation Engineering, Tarbiat Modares University \\ Tehran, Iran \\ B.eslamiziraki@modares.ac.ir \\ ${ }^{2}$ Karbala Project \\ Tehran, Iran \\ Va.ghasemi@yahoo.com
}

\begin{abstract}
Today population increase leads to an increased demand for reliable infrastructure. One of the challenges in deep excavation project is high level water table and deformation control of adjacent sensitive structures. The diaphragm wall technique (DW) is one of the alternatives that proposed for this condition. Development of Imam Hossein Shrine project has been constructed in Karbala, Iraq. In this paper, the performance of a 40 meter deep multi-propped excavation in medium to very dense sand and clay layers is studied. The vertical sidewalls of the excavation were supported by cast-in-place fully reinforced concrete diaphragm walls. In this project, the level of underground water table is high, so hydrolic uplift pressure at bottom of excavation is a problem, which two approaches were proposed. Scenario I was utilized the short external diaphragm wall and tension pile and scenario II was using the deep external diaphragm wall. Based on our results the second method has the benefits such as less cost and construction time as method I. To evaluation the performance of these methods a finite difference numerical simulation was developed by FLAC2D code.
\end{abstract}

Keywords: Deep excavation, Diaphragm Wall, uplift pressure, numerical simulation, FLAC2D

\section{Introduction}

By increasing the population and need to underground spaces the deep excavation must be constructed and these spaces serve as car park or shopping center. These constructions in urban environments must be sufficiently stable to maintain the excavation and near vulnerable structures. These structures may be built at locations below the water table which give the risk of the project. There are common methods to deep excavation below the water table that selection of them need to be study the soil condition by more accuracy. The diaphragm wall is a reasonable method that it was employed in this situation. In the last years the diaphragm wall has become a solution to construction of substructures in crowded urban areas. Diaphragm wall construction method is relatively quiet and caused little or no vibration. Especially, it is suitable for civil engineering projects in densely-populated inner city areas[1,2]. In construction of this type of wall, it is necessary to maintain the cavity full of slurry to keep the sides of the excavation from caving. The slurry used for these purpose is a type of bentonite (a montmorillonitic clay-mineral-based product), water, and suitable additives[3, 4]. Take out the excavation below the underground water accompany by problems such as displacements in near structures, failure of soil adjacent the panel excavation, and uplift pressure in bottom of structure. The Asioli was studied the anchored diaphragm wall for a car park basement and related problem of dewatering system in it project. In similar paper, no investigation was mentioned about the uplift pressure in diaphragm wall method. In current study, two various methods were studied to resisting against the uplift pressure in the development of Imam Hossein holly shrine project.

\section{Site specific condition and Geology of Karbala}

The holy shrine project is located in center of Karbala, Iraq, approximately $110 \mathrm{~km}$ from the Baghdad and $675 \mathrm{~km}$ from Persian Gulf. The plan of development includes the library, restaurant, museum, apron and emergency tunnel, that the site area is approximately $50,000 \mathrm{~m}^{2}$. 
Karbala holy shrine project consists of four phases that first one located in south-west direction that's called haram Apron (Fig 01). By considering the underground water table in this project, the diaphragm wall was a reasonable technique.

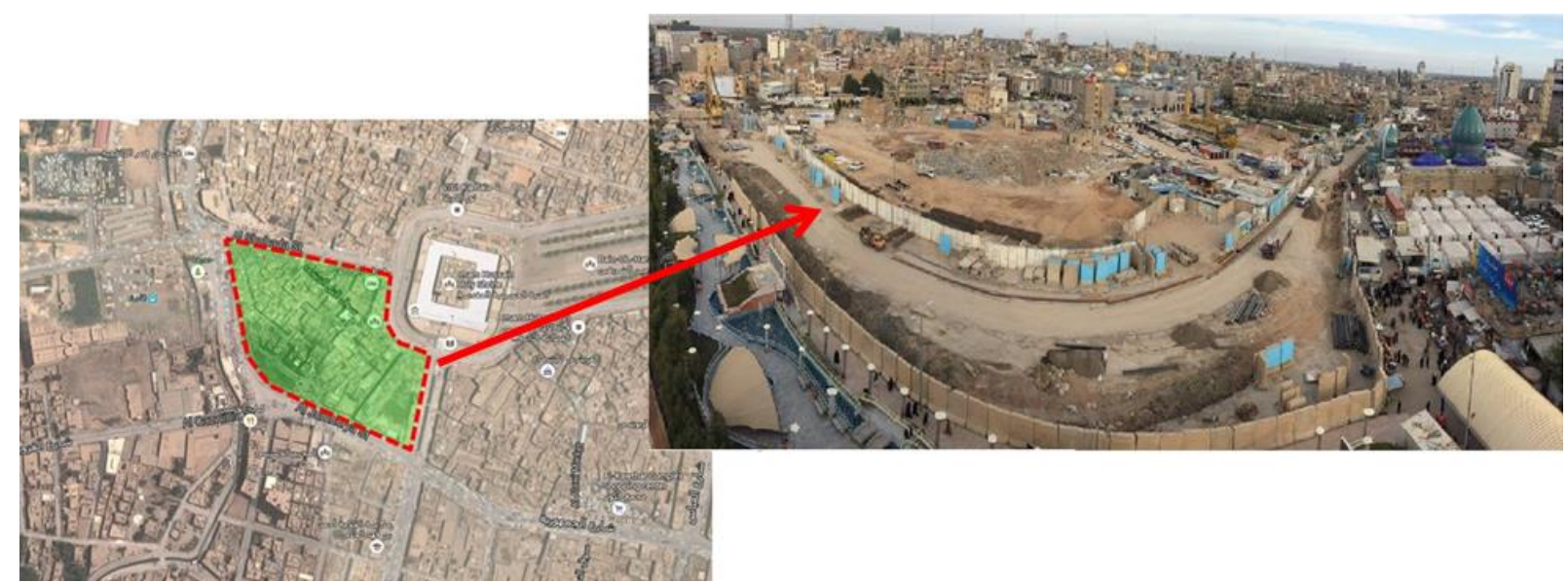

Fig. 1: Location of the Imam Hossein holy Shrine Development (Haram Apron).

The construction of the emergency tunnel no any interface by the major excavation in schedule, so it can be performed parallel to it.

The geotechnical soil classification and depth of layers are shown in Tab1. These data were taken out from numerous boreholes around the project. Boreholes have been performed by rotary and continue core drilling method that in all boreholes was performed the pressuremeter, plate load test (PLT), and in situ direct shear test. In this study, reported water table depths were ranging from 3 to 3.5 meters (10 to 12 feet).

Geologically, this project was located within the Quaternary alluvial zone and Dibidiba formation, it is sited on the Granit bedrock that related to the Precambrian era. The sediment in Karbala project is composed of fine grain sediment, gravel, sand, and rubble. The diaphragm wall construction was performed by a hydrofraise machine that its sequences is excavation, reinforcement and concrete of panels.

Table 1: Soil Charactristics in Karbala project.

\begin{tabular}{|c|c|c|c|c|c|c|c|}
\hline \multirow{2}{*}{ Depth } & \multirow{2}{*}{ Description } & Unit weight & \multirow{2}{*}{$\begin{array}{c}\text { Poisson } \\
\text { ratio }\end{array}$} & $\begin{array}{c}\text { Friction } \\
\text { angle }\end{array}$ & Cohesion & Young modulus & permeability \\
\cline { 5 - 8 } & & $\mathrm{KN} / \mathrm{m} 3$ & & $\mathrm{deg}$ & $\mathrm{Kpa}$ & $\mathrm{GPa}$ & $\mathrm{cm} / \mathrm{sec}$ \\
\hline $0-12$ & $\begin{array}{c}\text { Medium } \\
\text { dense }\end{array}$ & 19 & 0.28 & 30 & 12 & 50 & $1 \mathrm{E}-2$ \\
\hline $12-30$ & Sandy clay & 19.5 & 0.28 & 39 & 25 & 135 & $1 \mathrm{E}-2$ \\
\hline $30-37$ & Dense sand & 20 & 0.28 & 36 & 10 & 150 & $1 \mathrm{E}-4$ \\
\hline $37-50$ & Hard clay & 20 & 0.28 & 30 & 35 & 100 & $1 \mathrm{E}-5$ \\
\hline
\end{tabular}

\section{Diaphragm wall method}

Construction of substructures in urban areas was accompanied with deformation of surrounding ground and adjacent buildings, so it is essential to protect the pre-exiting structures and underground utilities from feature damage. Based on this purpose, it is utilized a continuous retaining concrete wall for stability of lateral wall. Toe of diaphragm wall embedded in the soil mass to act the wall as a cantilever element. On the other hand, the uplift pressure can be harmful for 
the main structures in deep excavation, that's located in high water table depths. The DW method involves sequential steps, which the soil is removed by "Hydrofraise" machine (BAUER company) and the bentonite applied the lateral pressure to avoiding the soil failure. The "Hydrofraise" is a drilling machine powered by three down-the-hole motors, operating with reverse circulation. A heavy metal frame, serving as a guide, is fitted at its base with two cutter drums carrying tungsten carbide tipped cutters. These rotate in opposite directions and break up the soil. A pump is placed just above the drums and excavated the loosened soil, which is carried up to the surface by the drilling mud. The mud with cuttings is continuously filtered (de-sander unit) and then poured back into the trench. This method is very efficient in the cases that the project located below the underground water. In cases, the excavation was performed in vast area this technique is a reasonable solution to substantial the sheet pile method. By considering the ground geology situation, near vulnerable buildings and dimension of this project the DW can be the best approach to construction of substructure.

The construction process of DW as described below:

- Performing the guide wall structure in top area of zone panel: Guide-wall is two parallel concrete beams running as a guide to the hydrofraze which is used for the excavation of the diaphragm wall. Excavation for the diaphragm wall produces a vertical strip in soil which can collapse easily.

- Sequence excavation of retaining wall by especial machine

- Excavation support using bentonite slurry: bentonite slurry is used to protect the sides of soi1. Bentonite is a naturally occurring clay which, when added to water, forms an impervious cake-like slurry with very large viscosity. The slurry will produce a great lateral pressure sufficient enough to retain the vertical soil.

- Insert reinforcement and concreting

- Excavation the next panel

\section{Uplift Pressure}

\subsection{Uplift mechanism}

The uplift pressure is flotation phenomena that caused due to the hydrostatic mechanism between upper and lower water table. All the major foundation design codes, the control of uplift pressure is mandatory at foundation level. In current study, there is high permanent underground water table due to lack of urban sewage system. Most common methods to overcome the uplift pressure are ground anchor, micro-pile, bored pile, post grouted pile, and increasing the dead load of structures [10]. To resist the uplift pressure in this study, two reasonable techniques were suggested below:

\subsubsection{Solution I: Short diaphragm wall and Tension piles}

In first solution, the combination of tension piles and out DW by depth 30 meter was considered. That this scenario was determined based on the general stability of excavation criteria. The tension piles performed at bottom of foundation to solving the uplift pressure problem. Generally the uplift pressure is a type of hydrostatic pressure, which according to the water table in this project (Pore pressure of numerical analysis) there will be about $120 \mathrm{kPa}$ uplift pressure. The dead load due to the structures that constructed in features ( 5 floors) is not sufficient to overcome this pressure. By considering the simplicity of bored piles implementation, the group piles by distance 4 and diameter 1 meter was selected. The required length for piles in this condition must be equal 22 meter. In tension piles, the resistance to uplift is provided by the friction or adhesion between the pile skin and the surrounding soil that it is related to type of soil and pile installation method. Based on soil profile, the shear parameters of soil are so weak, which this was leads to more length of these piles. On the other hand, the material of piles was one of the problems, since based on the condition of environment the corrosion may be happened in these piles, and reinforcement concrete was selected as pile type. Also based on reported site investigation, there is phreatic level 3 meter below the surface permanently, so a draining system must be embed under the foundation after final excavation. It must be noted that the inner DW height is about 20 meters in these proposed techniques.

\subsubsection{Solution II: Outer Deep diaphragm wall}

Based on the site investigation, a dens sand cemented lense was observed in-depth of 37 meter that its permeability is less than the top layers, so by passing the toe of outer DW through this layer it can be control the uplift pressure at substructure level. In fact this solution lead to increasing the length of flow net and decreasing the pore pressure (See Fig2). 
The diaphragm wall by $1000 \mathrm{~mm}$ thick, with a depth up to 40 meters, provided a continuous temporary structure to prevent soil collapse and water inflow during the digging works. In Haram Apron a double DW structure was considered, which these DW wall were connected together by two flat slabs. The outer wall has 40 meter and the interior 20 meter depth that this depth calculated based on the stability of the wall. Operation of DW by this pattern was lead to decreasing the hydraulic gradient at the substructure, and control of water discharge into the excavation. The top slab has $1000 \mathrm{~mm}$ thickness that joined the outer and inner wall together that this is lead to less slender of external wall and less horizontal displacement. The emergency tunnel was located between these walls. The section of diaphragm wall structure was illustrated in Fig3. In the final construction, a mat foundation with drainage system was performed under foundation level. The respective total excavation volume and depth of haram apron phase are about $636000 \mathrm{~m}^{3}$ and $14.2 \mathrm{~m}$.

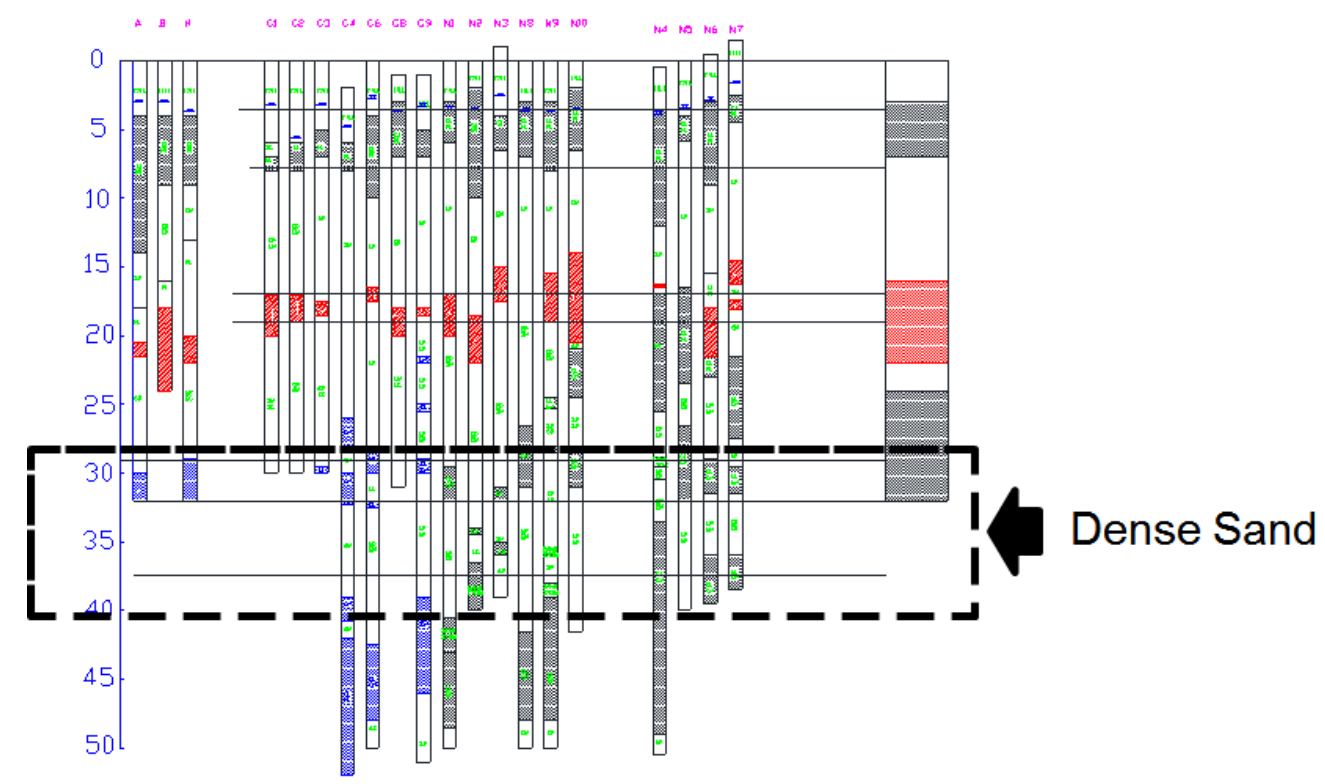

Fig. 2: Detail of the geotechnical profile of the site (location of dens sand).
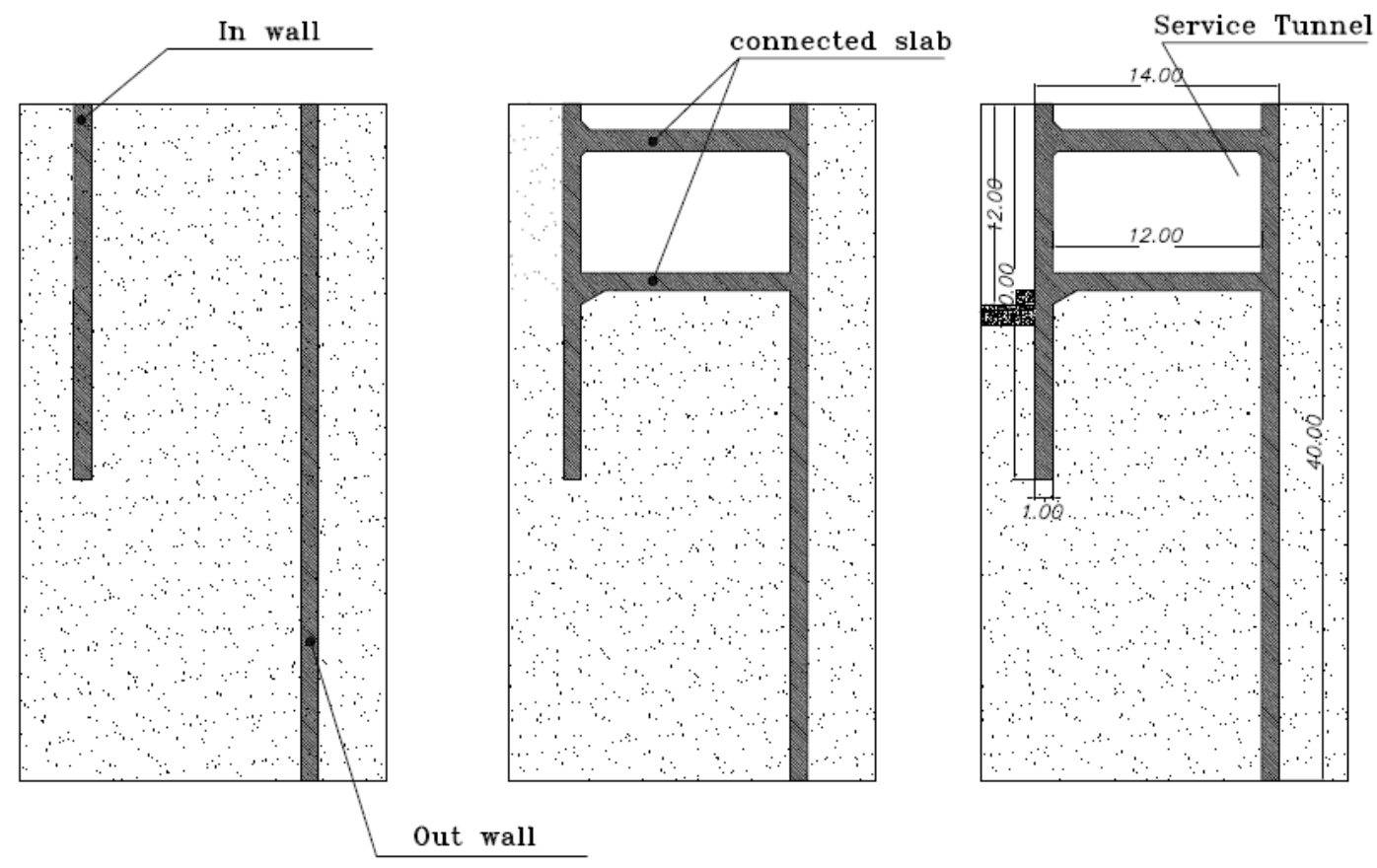

Fig. 3: Sequential excavation of Haram apron excavation. 


\section{Numerical simulation}

In diaphragm wall analysis, the earliest method proposed by Blum to analysis the diaphragm wall in simple geometrical condition, but in complex situation, the numerical technique can be a powerful gadget to studying the DW performance. In this study, the 2D finite different method (FDM) was developed to simulation of real condition and sequence of DW structure (FLAC2D ver6.) [5].To decreasing the effect of virtual borders on the results, it has considered the geometric dimensions of the model as $6 \times \mathrm{H}$ (Longitudinal), and $6 \times \mathrm{H}$ (Transverse. These dimensions determined based on parametric analysis to decreasing the boundary effect on the result (H equal to depth of excavation) (Fig4). The lateral borders in sides of the model simulated by roller and this border at bottom is fix support. The reported water table in this project was range 3 to 3.5 meter below surface, so the couple hydro-mechanical analysis was done in numerical analysis. Based on the real parameters of the structural elements, the diaphragm wall body was modelled as solid element by elastic model. To develop the model, it has been used the Mohr-Coulomb constitutive model [6, 7].

An uniform distributed load of $20 \mathrm{KPa}$ applied as the traffic and adjacent structures load. In the simulation process, the outer and inner diaphragm wall panels were installed in ground firstly, then the soil was removed in the service tunnel area. After that the major excavation was performed finally. The model was developed based on the real progressive excavation pattern, through which the deep excavation was simulated sequentially[8]. The structural element properties in this project were presented in Tab2. In this project, since the diaphragm wall was constructed in long length, so the analysis was done based on plain-strain condition ( 2 dimension analysis). The horizontal displacement beside the outer DW was showed in Fig 5. [9].

Table 2: Diaphragm wall elements characteristics in Q7-station.

\begin{tabular}{|c|c|c|c|c|c|}
\hline element & Young modulus(GPa) & Poisson ratio & Unit weigh(KN/m3) & Thickness(cm) & Depth $(\mathrm{m})$ \\
\hline Internal-DW & 20 & 0.20 & 24.00 & 100 & 20.0 \\
\hline External-DW & 20 & 0.20 & 24.00 & 100 & 40.0 \\
\hline Top beam & 20 & 0.20 & 24.00 & 120 & 4.00 \\
\hline
\end{tabular}

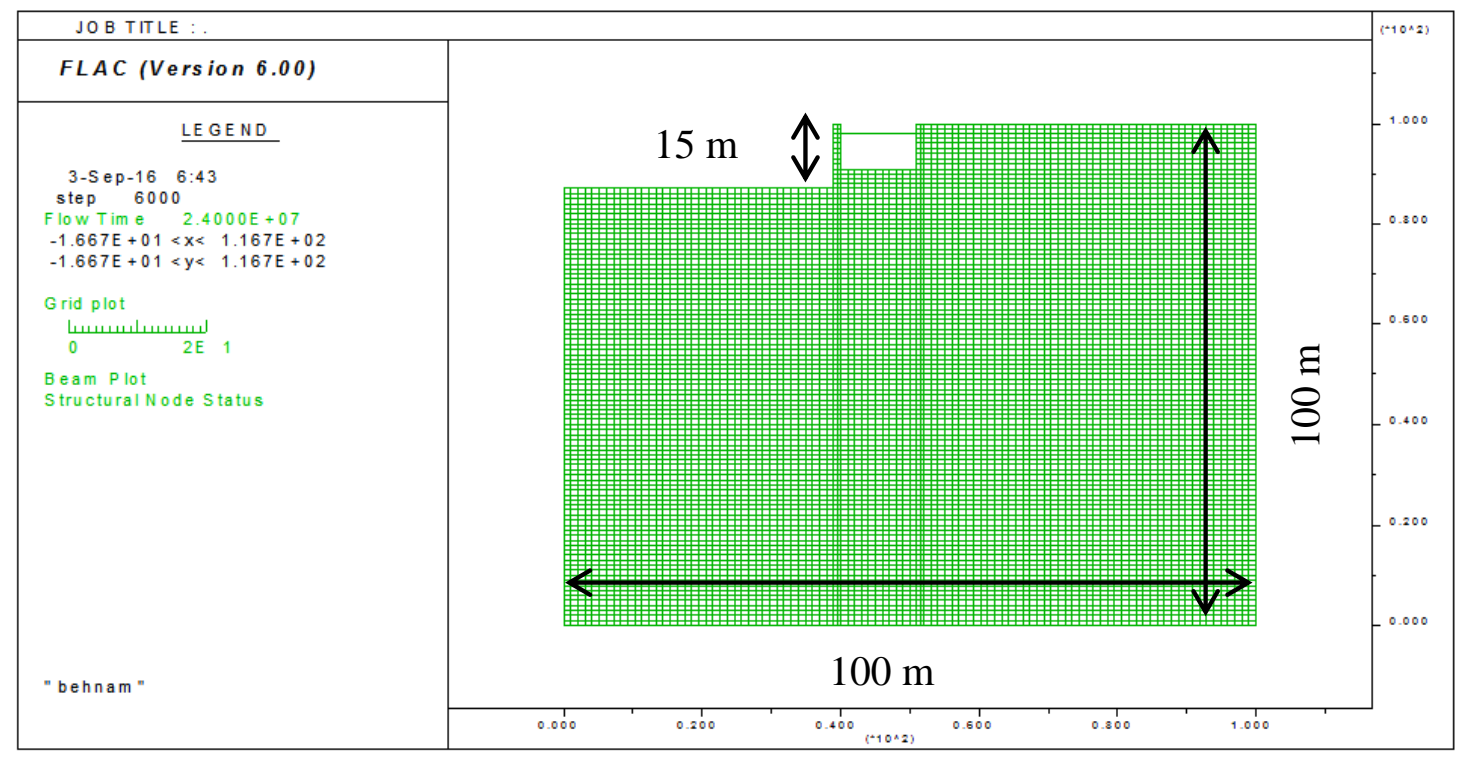

Fig. 4: FDM model of Diaphragm Wall. 


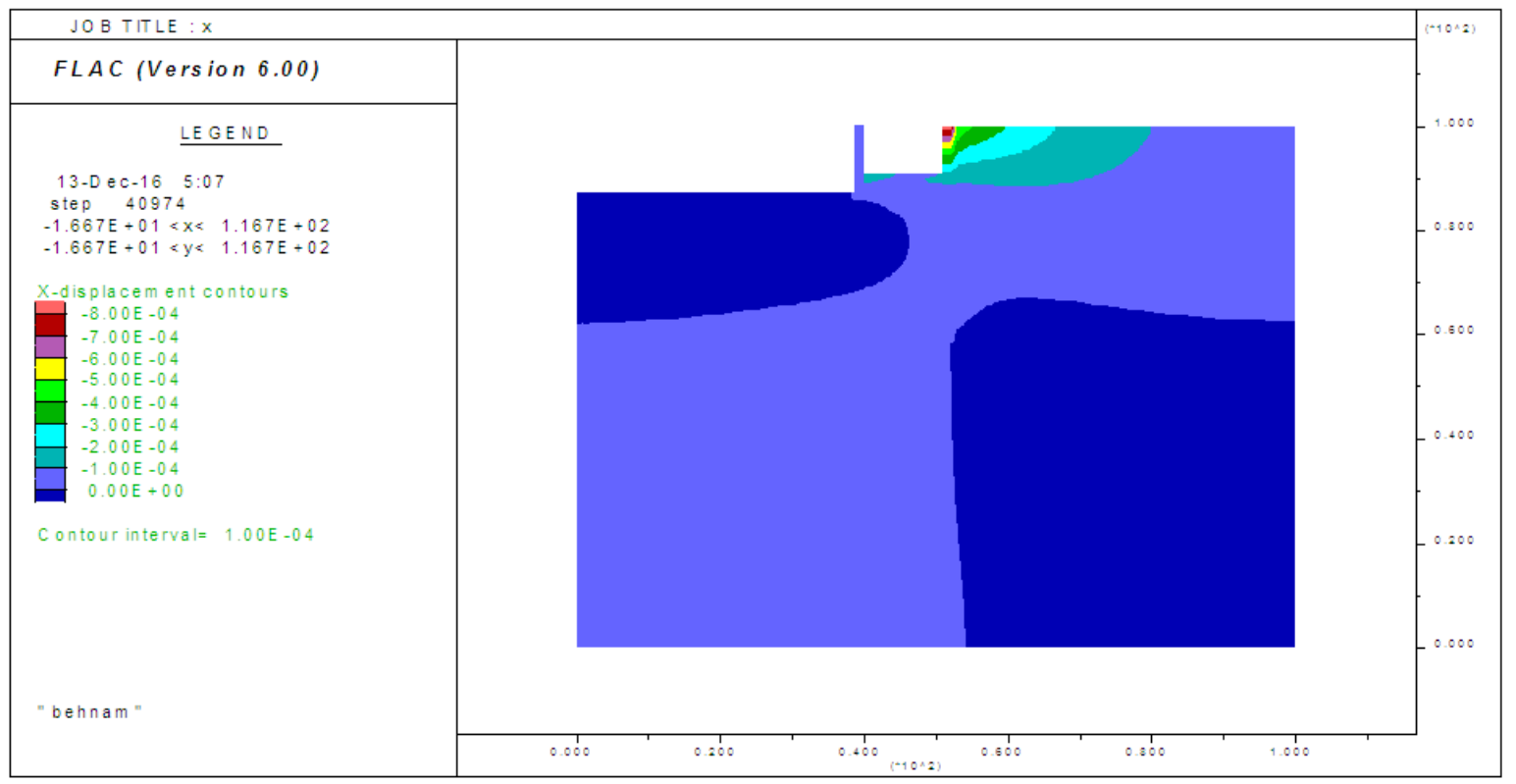

Fig. 5: Horizontal displacement in soil mass after station excavation.

The vertical displacement and pore pressure was comprised together that that's results showed the performance of various methods (Fig 6,7).

Based on these results, there are two scenarios to overcome the uplift pressure at bottom of Karbala project level. In scenario I, the outer and inner DW were constructed by 20, 10 meter depth, that it was required to added the tension piles to overcome the uplift pressure. The accumulated force of tension piles was dependent to the lateral resistant, and installation method. Based on the result of logging boreholes, there are layers by low cohesion under the foundation, so it is lead to high pile length. Furthermore, there is more discharge flow to the excavation. The final cost of deep outer DW was compared to short DW wall by tension piles, that this comparison was illustrated in Fig8. Cost comparison of these methods was proved the preference of second technique. The final cost of these methods was determined based on material, work wages, machinery, and transport costs.

If the out DW passes through this layer by low permeability (scenario II), it can be disrupted the downstream flow. The benefits of second method construction were outlined below:

- Low cost and time of the excavation

- Undisturbed the underground water table regime, which it is lead to promoting the environmentally criteria of the project

- Decline the flow discharge can be increased the scouring risk under the foundation

- Less settlement for near structures by controlling the underground water table

- Less complexity of the draining system in substructure 


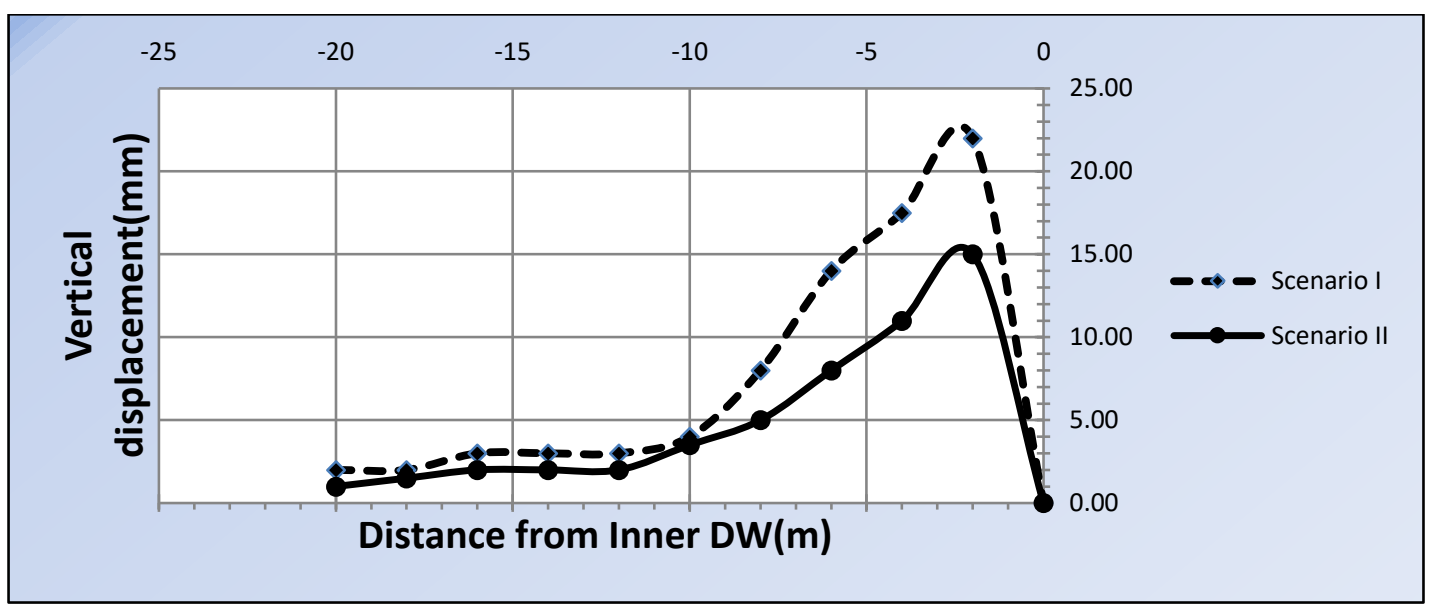

Fig. 6: Comparison the vertical displacement (deep DW and short DW \& pile).

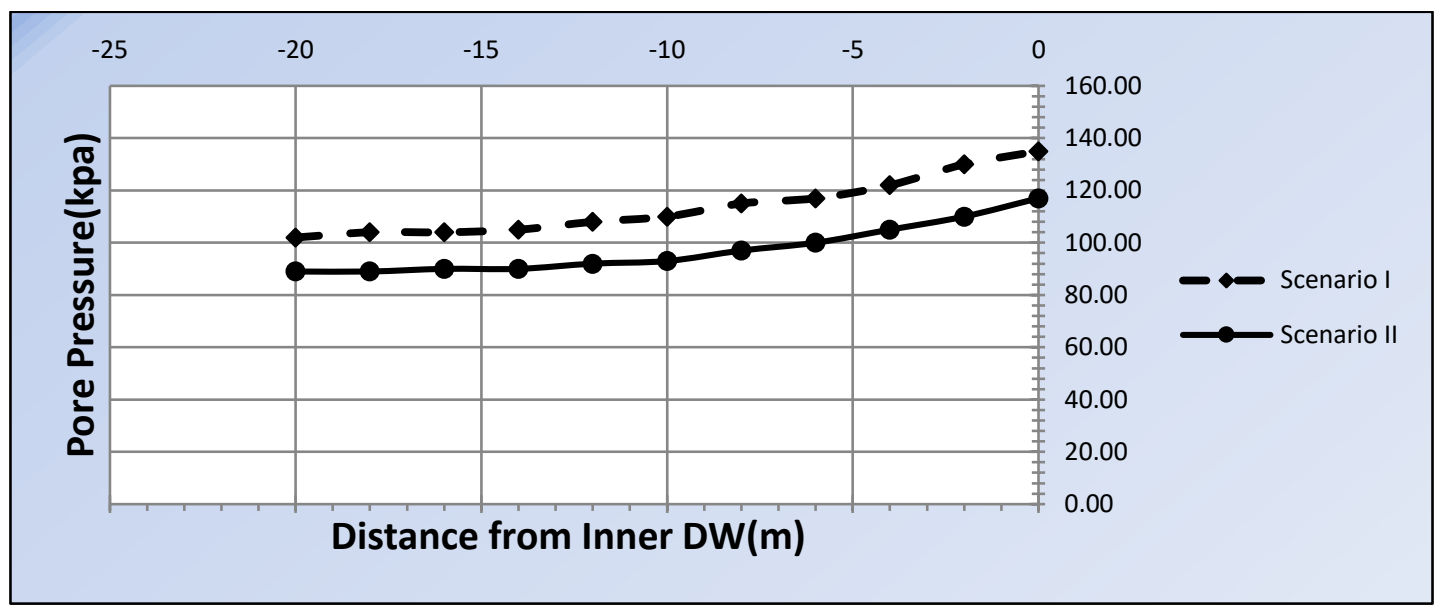

Fig. 7: Comparison the pore pressure (deep DW and short DW \& pile).

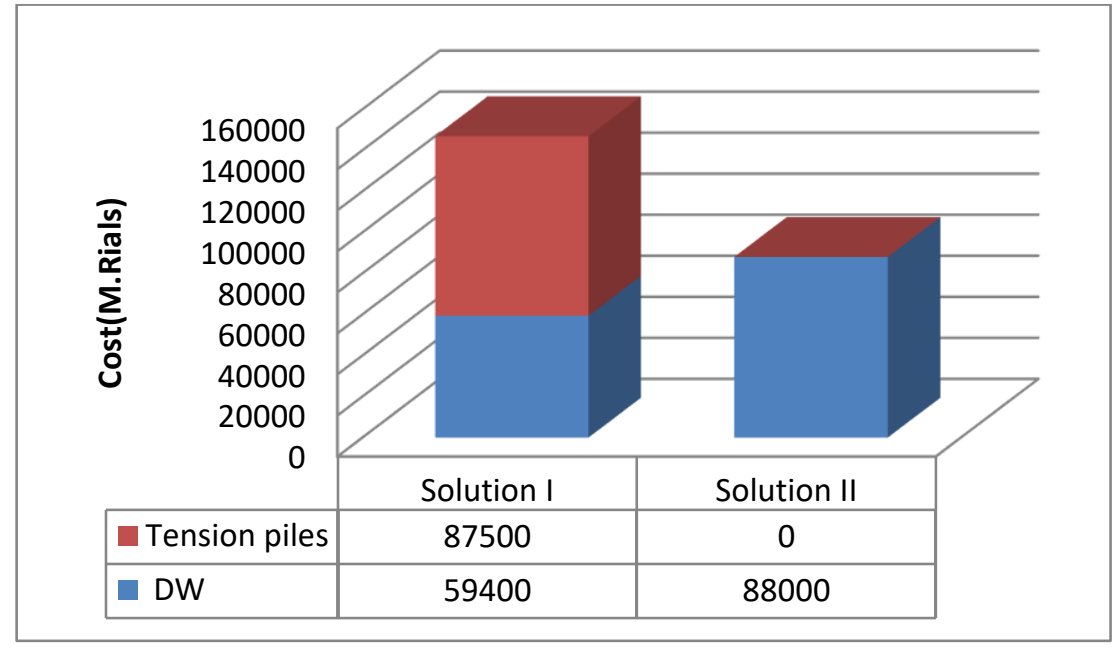

Fig. 8: Comparison of final cost. 


\section{Conclusion}

In this paper discussed the performance of the diaphragm wall for an underground multi-story, which it is constructed in congested downtown Karbala. Also the collection geotechnical database has been played a major role in make decision. Selection the best alternative dependent on the site investigation information. Construction the deep DW can decrease the uplift pressure in bottom of excavation and decreased the final cost of project. This technique is lead to the low flow discharge in to the excavation and decreased the hydraulic gradient at bottom of substructures. Environmentally, by construction the deep DW that passes through a dense sand layer, the natural condition of underground water table will be maintained and this lead to less surface settlement near the adjacent vulnerable structures. The most important benefit, the time and cost of the project will be declined, since the more activities can be done parallel together based on comprised scheduled.

\section{Acknowledgment}

Hereby, we gratefully acknowledge Pars Geometry Consultant for providing the monitoring data and for his technical support during the investigation.

\section{References}

[1] E. Pujades, et al., "Dewatering of a deep excavation undertaken in a layered soil," Engineering geology, vol. 178, pp. 15-27, 2014.

[2] C. Asioli, Geotechnical Aspects of Underground Construction in Soft Ground. CRC Press, 2012.

[3] J. E. Bowles, Foundation analysis and design, McGraw Hill, 1988.

[4] T. D. Richards Jr., Diaphragm walls, 2006.

[5] N.-M. Ilieş, V.-S. Farcaş, and M. Pop, "Design Optimization of Diaphragm Walls," in Procedia Technology, vol. 19, pp. 357-362, 2015.

[6] H. Ranjan and S. Rao, Analysis of the Effect of Anchor Rod on the Behavior of Diaphragm Wall Using Plaxis 3d, Aquatic Procedia, vol. 4, pp. 240-247, 2015.

[7] M. S. Pakbaz, S. Imanzadeh, and K. Bagherinia, "Characteristics of diaphragm wall lateral deformations and ground surface settlements: Case study in Iran-Ahwaz metro," Tunnelling and Underground Space Technology, vol. 35, pp. 109-121, 2013.

[8] A. Rahman and M. Taha, "Geotechnical performance of embedded cast-in-situ diaphragm walls for deep excavations," Slovak journal of civil engineering, vol. 3, pp. 30-38, 2005.

[9] Y.Arai, et al., "A numerical study on ground displacement and stress during and after the installation of deep circular diaphragm walls and soil excavation," Computers and Geotechnics. vol. 35, no. 5, pp. 791-807, 2008.

[10] I. Wong, "Methods of resisting hydrostatic uplift in substructures," Tunnelling and Underground Space Technology, vol. 16 , no. 2 , pp. $77-86,2001$. 